\title{
FLOW OF RUTFORD ICE STREAM AND COMPARISON WITH CARLSON INLET, ANTARCTICA
}

by

\author{
R.M. Frolich, D.G. Vaughan, and C.S.M. Doake
}

(British Antarctic Survey, Natural Environment Research Council, High Cross, Madingley Road, Cambridge CB3 OET, England, U.K.)

\section{ABSTRACT}

Results from movement surveys on Rutford Ice Stream are presented with complementary surface-elevation and ice-thickness measurements. Surface velocities of $300 \mathrm{~m} \mathrm{a}^{-1}$ occur at least $130 \mathrm{~km}$ up-stream of the grounding line and contrast strongly with the neighbouring Carlson Inlet, where a velocity of $7 \mathrm{~m} \mathrm{a}^{-1}$ has been measured. This contrast in velocity is not topographically controlled but appears to be due instead to differences in basal conditions, with Carlson Inlet probably being frozen to its bed. Concentration of lateral shear close to the margins and surface expression of subglacial topography both support a view of significant basal shear stresses in the central part of Rutford Ice Stream. The pattern of principal strain-rate trajectories shows a small number of characteristic features which can be compared with results from future modelling of the glacier's flow.

\section{INTRODUCTION}

Rutford Ice Stream is a fast-flowing outlet glacier which drains about $36000 \mathrm{~km}^{2}$ of the West Antarctic ice sheet into Ronne Ice Shelf (Fig. 1). It has been the subject of two ground-based surveys in the periods 1978-80 and 1984-86, during which 239 survey stations were established along a $150 \mathrm{~km}$ section extending $20 \mathrm{~km}$ down-stream of a grounding line. Ground-based and airborne radar sounding have provided ice-thickness measurements over most of this area. These survey networks have been described and some

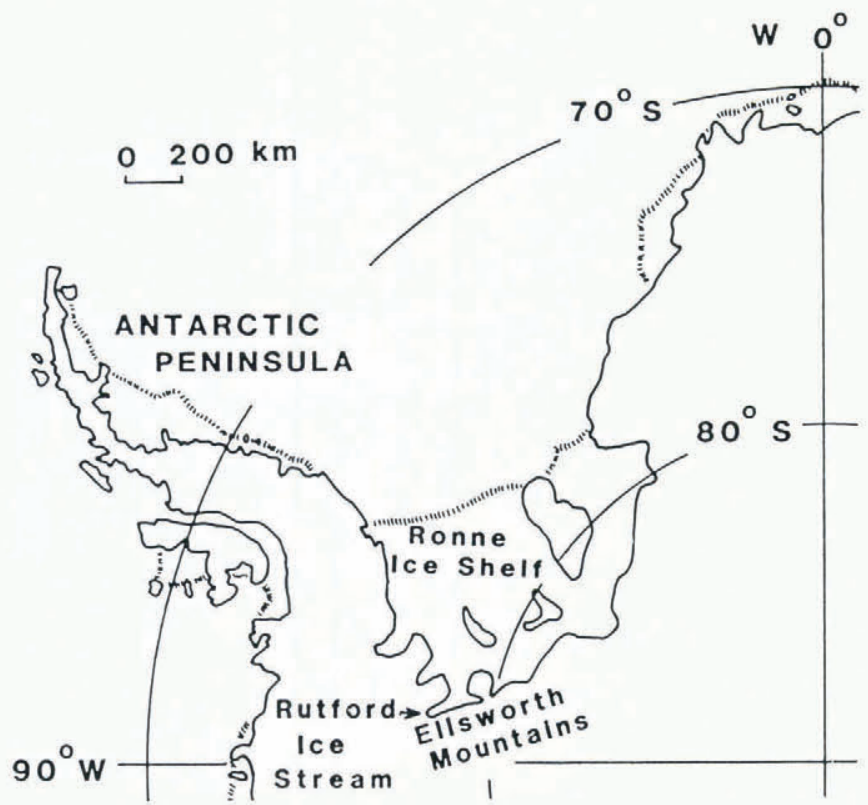

Fig. 1. Location map. interpretations have been given by Stephenson and Doake (1982) and Doake and others (1987). The influence of the various restraining forces that may balance the gravitational driving force has been investigated for a $60 \mathrm{~km}$ section a short distance above the grounding line, and data from three transverse lines (C, D, and $\mathrm{E}$ in Figure 2) used to

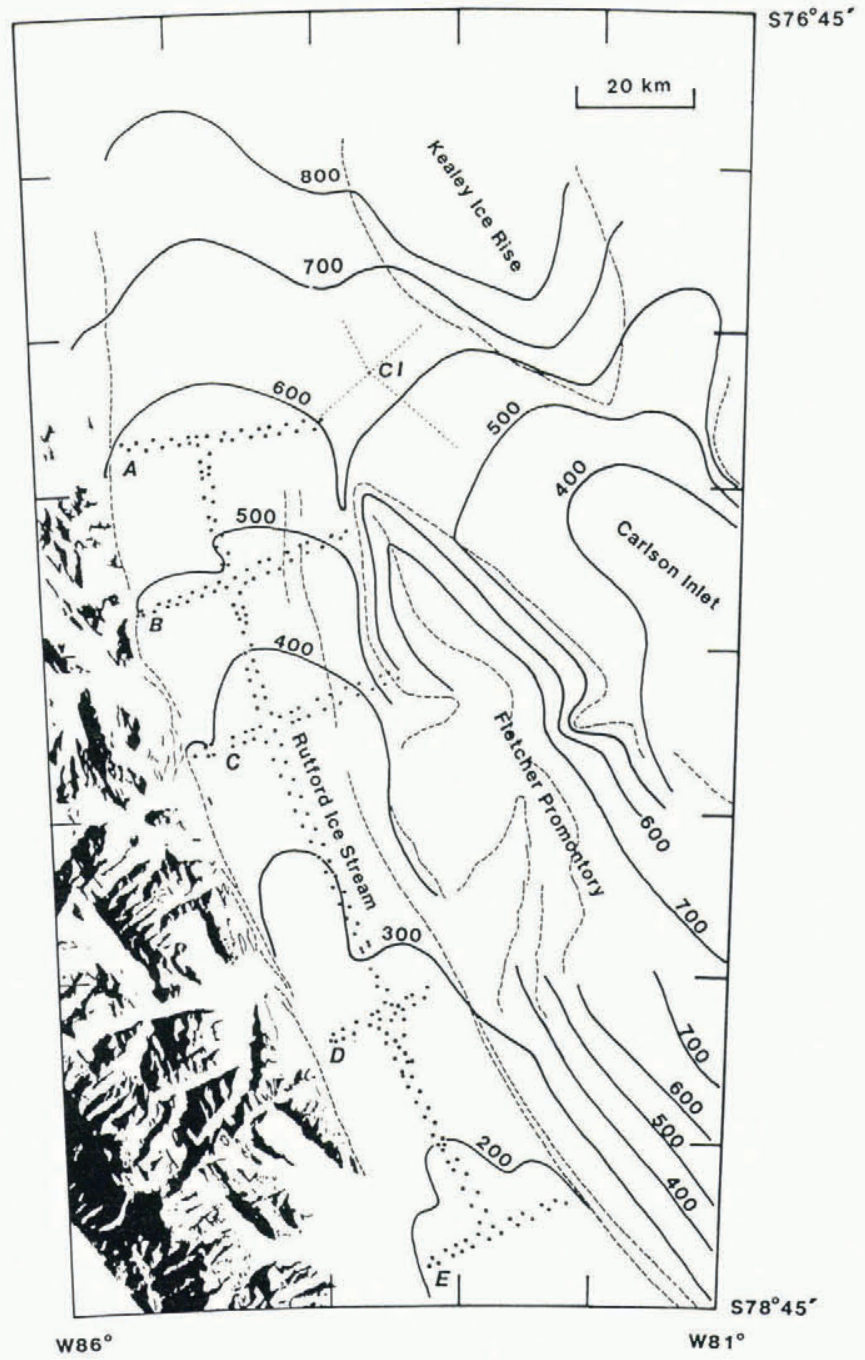

Fig. 2. Surface topography map of Rutford Ice Stream and Carlson Inlet. Solid lines are elevation contours in metres above WGS72 ellipsoid. Dashed lines are form lines derived from Landsat images. Dots denote stake positions and dotted lines show traverses on Carlson Inlet. Transverse lines are labelled A-E and Carlson Inlet doppler-satellite station is marked CI. The Ellsworth Mountains form the western boundary to Rutford Ice Stream. 
assess the importance of side-wall shear in this area (Frolich and others, 1987; Frolich and Doake, in press).

Since these initial studies, the reduction of the complete set of observations, including TRANSIT satellite-tracking data as geodetic control, has been completed. The results of the movement surveys are now presented in their entirety, along with some interpretations of the observed flow patterns and measurements from the neighbouring Carlson Inlet for comparison.

At the junction between Rutford Ice Stream and Carlson Inlet (shown on Figure 3), Doake and others (1987) described a clear linear feature on the satellite image which apparently separates the ice flow in the two glaciers. They suggested that the lack of visible surface undulations on the Carlson Inlet side of this feature may indicate lower ice velocities than on Rutford Ice Stream, where undulations on a scale of a few kilometres are clearly seen. The juxtaposition of a fast-flowing glacier with an almost stationary one is seen elsewhere in Antarctica, most notably on the Siple Coast where Ice Streams B and C have been intensively studied (Whillans and others, 1987). These appear to be out of balance with their respective (adjacent) catchment areas and therefore are experiencing non-steady flow. By comparison, there is no reliable estimate for the catchment area of Carlson Inlet, although a value considerably smaller than our estimate for Rutford Ice Stream would seem appropriate and consistent with a significantly lower surface velocity. To investigate this junction, ice velocity was measured at site CI in Figure 2, ice thickness was measured across the glacier, and surface elevation was measured both across- and down-glacier.

As well as presentation of longitudinal and transverse profiles of measured quantities, characterization of a flow pattern in terms of strain-rate trajectories and identification of its isotropic points can provide a useful description of the flow field. In a two-dimensional field of strain-rate or stress, isotropic points occur where $\dot{\varepsilon}_{x x}=\dot{\varepsilon}_{y y}$ and $\dot{\varepsilon}_{x y}=0$. At these singular points, strain-rate trajectories form characteristic patterns which can be classified into three possible types: lemons, stars, or monstars (Nye, 1983). Nye has told us that these features are structurally stable with respect to small changes in ice velocity, suggesting that such a description of an observed flow field could provide a reliable assessment of any produced by modelling. It is with this in mind that we present our interpretation of the pattern on Rutford Ice Stream.

\section{SURVEY RESULTS}

The survey network established in 1978 comprised two transverse double lines of aluminium poles ( $D$ and $E$ in Figure 2) joined by a $40 \mathrm{~km}$ longitudinal line. A grounding line was identified by measurements of tidal flexure about half-way along the longitudinal line (Stephenson, 1984). The 1984-86 network was established up-stream of the earlier one and comprised three transverse double lines (A, B, and $\mathrm{C}$ on Figure 2) joined by a $110 \mathrm{~km}$ line which overlapped the earlier one by $10 \mathrm{~km}$. On Figure 2, contours of surface elevation have been estimated from a combination of ground-based survey measurements and airborne altimetry. Profiles of surface elevation and of bed elevation obtained from radar sounding are shown in Figures 4 and 5 .

Whereas, for overall control, the 1978-80 survey relied on observations made from stations on the glacier surface to reference objects in the Ellsworth Mountains, the tracking of TRANSIT satellites in 1984-86 enabled a geographically based coordinate system to be adopted.

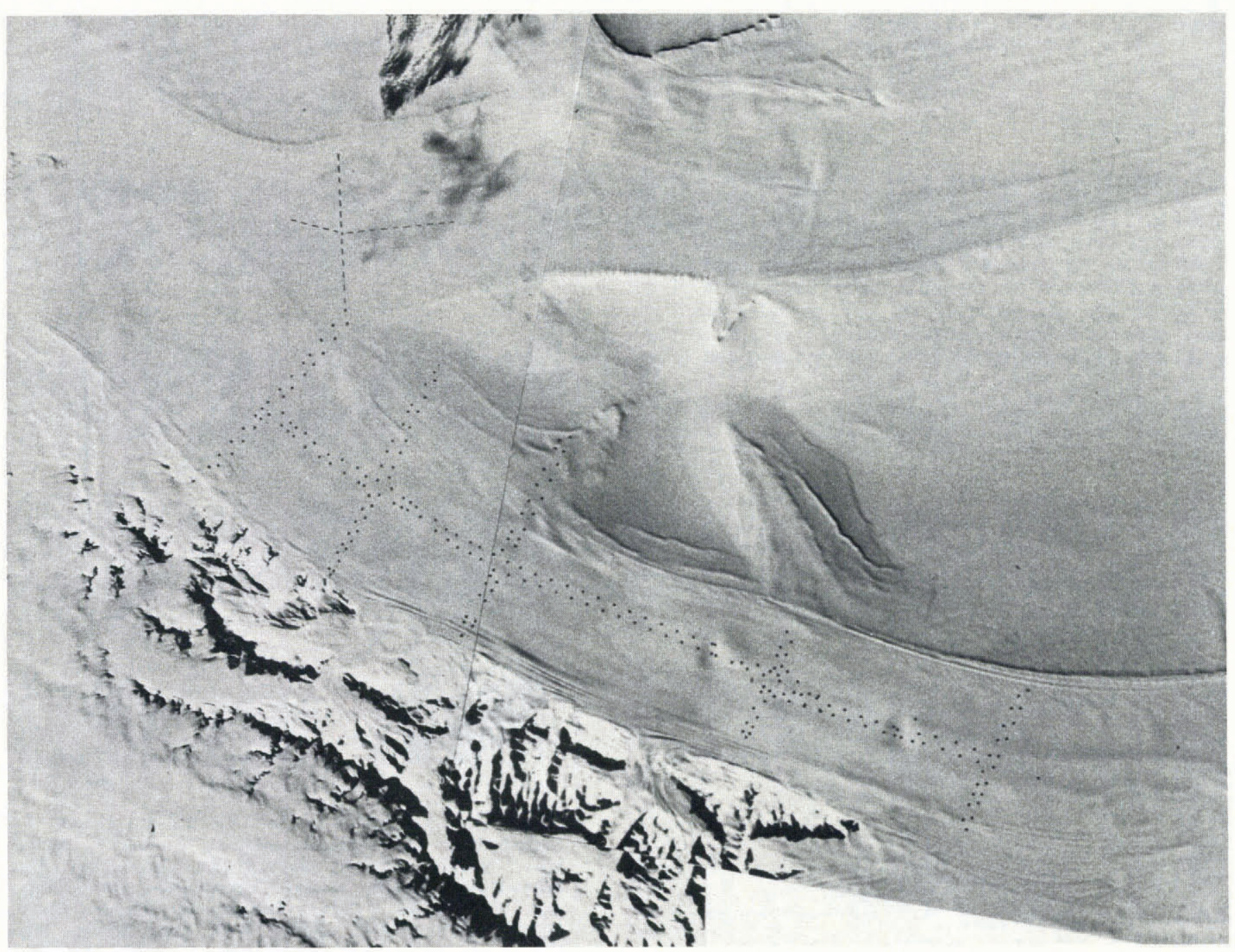

Fig. 3. Landsat image of Rutford Ice Stream and Carlson Inlet. Dots denote stake positions and pecked lines show traverses on Carlson Inlet. 


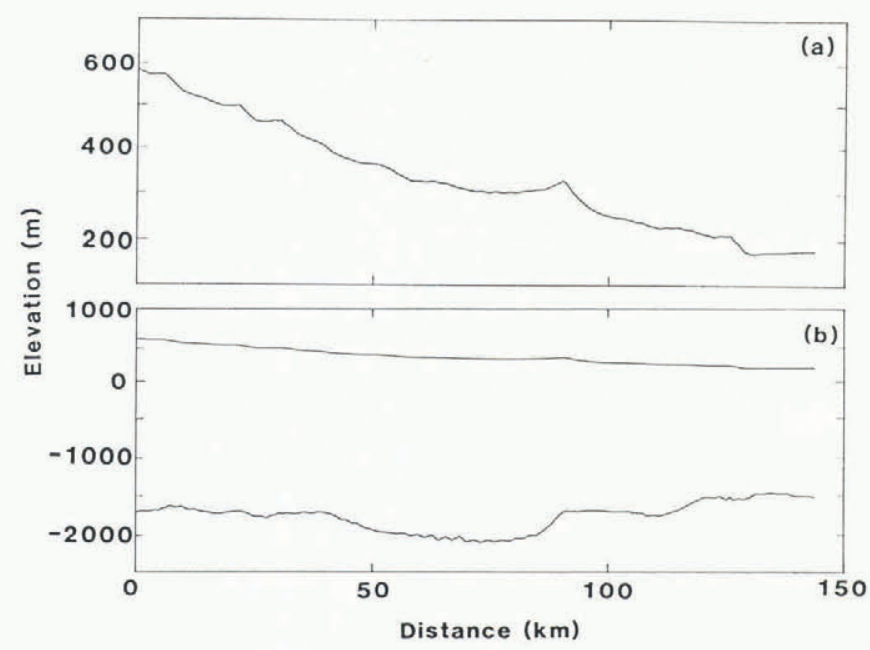

Fig. 4. (a) Surface elevation (above WGS72 ellipsoid) along the longitudinal line. Values are plotted for centroids of triangles composed of three neighbouring stakes.

(b) Surface and base elevations along the longitudinal line. In places where lateral gradients are large compared with the longitudinal ones, a periodic oscillation can be caused because alternate centroids are offset.
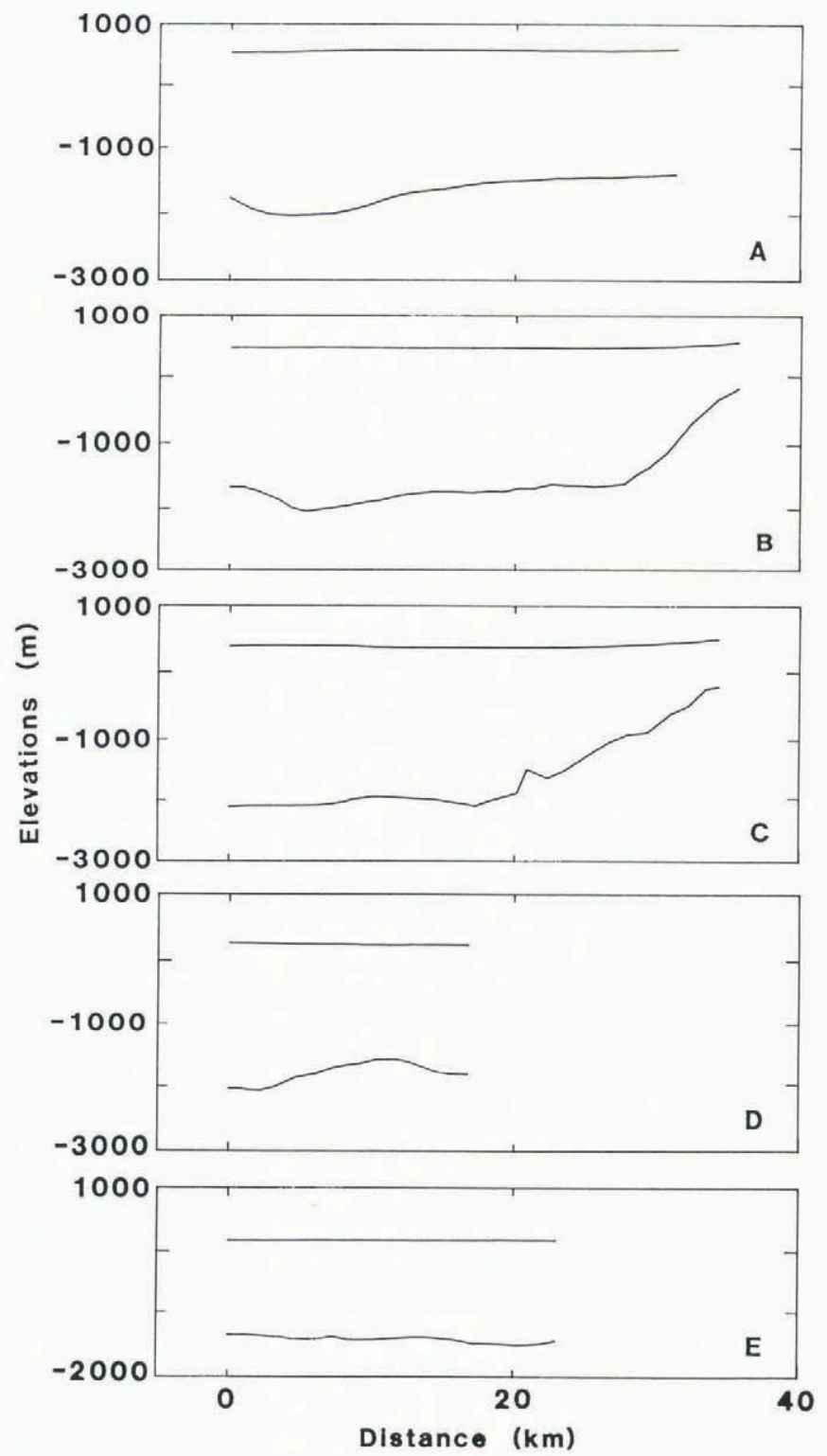

Fig. 5. Surface and base elevations across transverse lines $\mathrm{A}-\mathrm{E}$. Values are plotted for centroids of triangles composed of three neighbouring stakes.
Some station velocities obtained from field-processed doppler data were presented by Doake and others (1987) The data have since been re-processed using precise ephemerides to provide more reliable point positions, and these positions have been combined with conventional survey measurements in the solution of time-dependent observation equations using a method similar to that of Wager and others (1980). The positions calculated using precise ephemerides frequently differ from those using broadcast ephemerides by over $20 \mathrm{~m}$. They are also in much better agreement with the relative positions and velocities obtained using conventional ground-based measurements alone.

Although three of the aluminium poles used as station markers in the earlier survey were located in December 1984 (most of the others were probably buried), we cannot assume their velocities have been constant over such a long intervening period, and then reduce the two sets of observations as one in a simple way. The surveys have therefore been computed independently and subsequently combined using measurements made in the area where they overlap, providing geographical coordinates for stations in the earlier survey.

Results from the movement surveys are shown for the longitudinal lines in Figure 6, and for the transverse lines in Figure 7. In Figure 7, the two profiles for each transverse line represent components of velocity parallel and perpendicular to the average velocity direction.

Where the two surveys overlap longitudinally (their lateral separation is up to $3 \mathrm{~km}$, decreasing to zero at the down-stream end), Figure 6 shows a disagreement in velocity magnitude of between 5 and $7 \mathrm{~m} \mathrm{a}^{-1}$. Velocity magnitudes for stations on the later survey appear consistently greater than those for similar positions in the earlier one.

Errors in survey observation and in point positioning with TRANSIT satellite-tracking data both contribute to errors in computed values for positions and velocities. The use of precise ephemerides and the relatively small area involved help to reduce the satellite-tracking errors, but McDonald and Whillans (in press) recommended caution in interpreting formal errors in the solutions (generally about $\pm 2 \mathrm{~m}$ here) as measures of accuracy and point out that systematic problems could contribute further to overall inaccuracy. Errors from the survey reduction in the velocity magnitudes are about $\pm 3 \mathrm{~m} \mathrm{a}^{-1}$ and are independent between surveys. Errors in the relative positions of stations in different surveys could be up to $5 \mathrm{~m}$ in the area where the surveys overlap but, because the velocity gradients here are not more than $10^{-3} \mathrm{a}^{-1}$, any positional errors contribute little to a difference in velocity magnitudes over short distances.

Figure 8 shows profiles of bed and surface elevations along a line crossing Carlson Inlet from the eastern end of transverse line A to Kealey Ice Rise (sic). Surface elevations were measured by barometry and tied to the values obtained at the end of transverse A from the main survey, and at site CI from TRANSIT satellite tracking. Ice thicknesses were measured by ground-based radar sounding.

At site CI on Carlson Inlet, a velocity of $7.2 \mathrm{~m} \mathrm{a}^{-1}$ along a bearing $160^{\circ}$ true was measured by pointpositioning with precise ephemerides over an interval of 1 year. Formal errors for the point-positioning were $\pm 2 \mathrm{~m}$, however, so the orientation error could be $20^{\circ}$ or more.

Analysis of network survey data provides values for the magnitude and directions of the principal components of

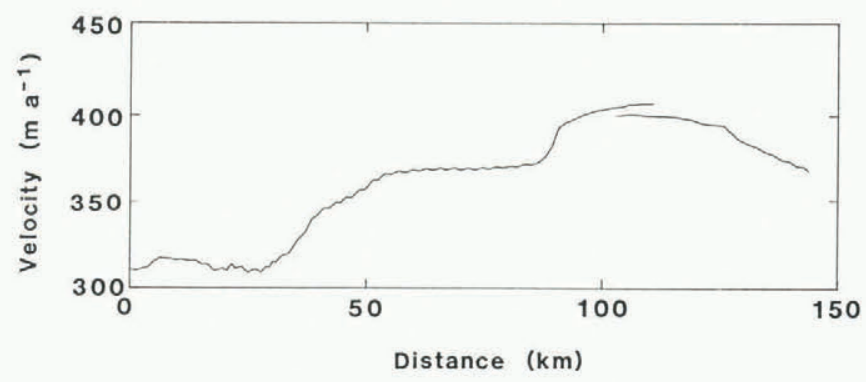

Fig. 6. Surface velocity for longitudinal line. Values are plotted for centroids of triangles composed of three neighbouring stakes. 

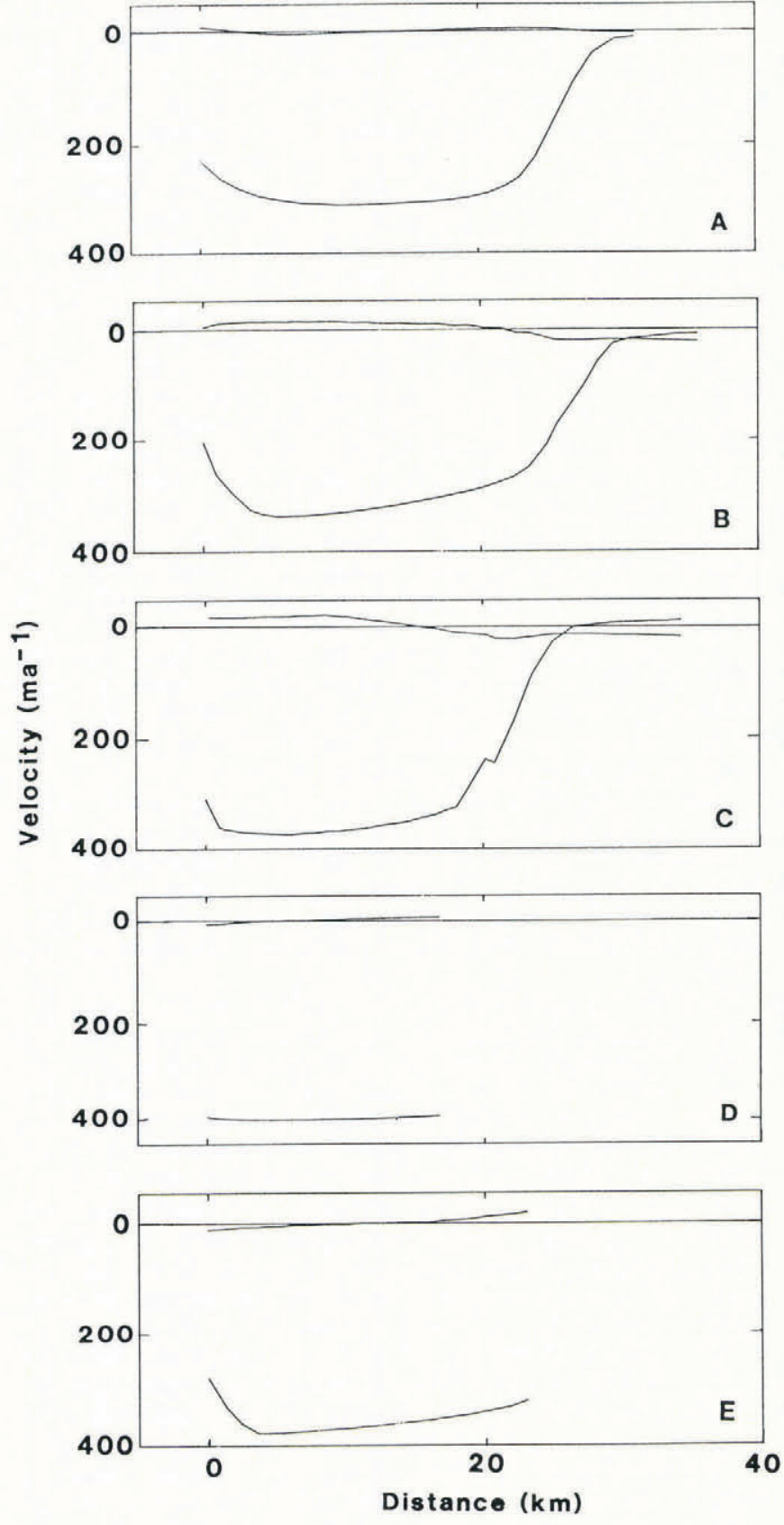

Fig. 7. Components of surface velocity parallel and perpendicular to the average velocity for transverse lines A-E. Values are plotted for centroids of triangles composed of three neighbouring stakes. For the perpendicular component, a profile sloping upward to the right indicates divergent flow, and one sloping downward to the right indicates convergent flow.

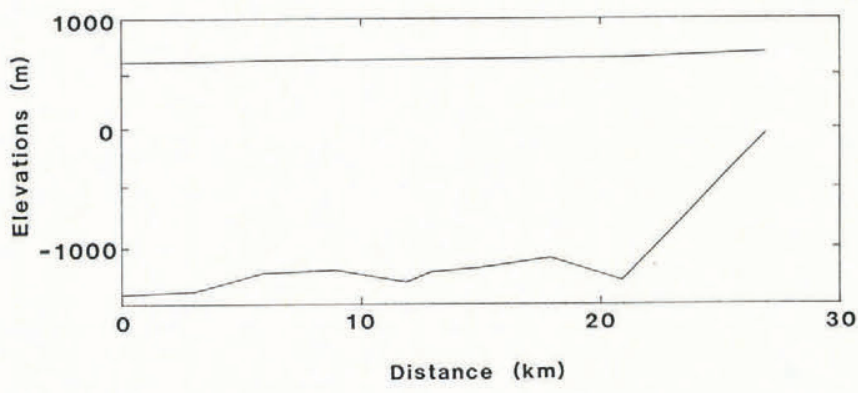

Fig. 8. Surface and base elevations for transverse line A continued across Carlson Inlet to Kealey Ice Rise (sic).

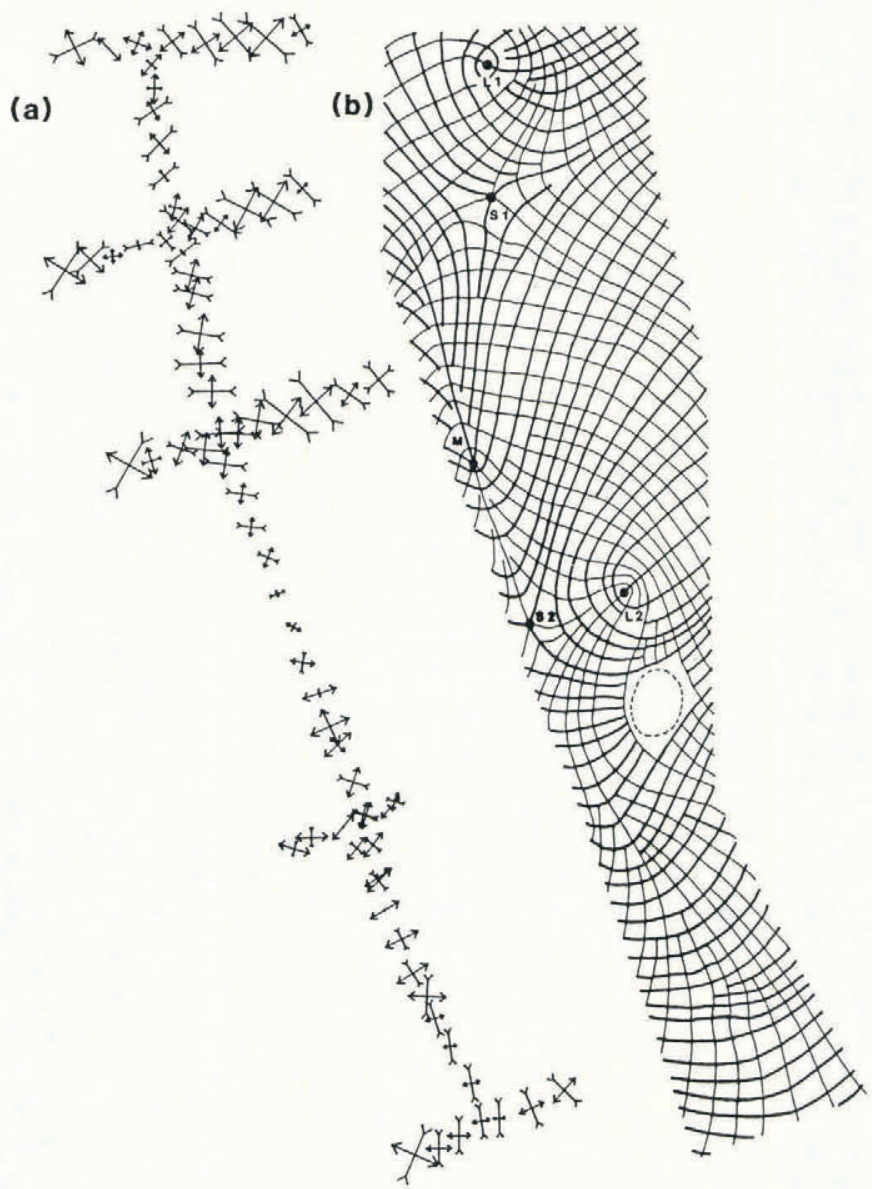

Fig. 9. (a) Principal components of strain-rate tensor at selected sites (one in three). A logarithmic scale has been used to help delineate the pattern.

(b) Pattern of strain-rate trajectories (maximum strain-rate indicated with heavy lines). Isotropic points are labelled $\mathrm{L} 1, \mathrm{~S} 1$, etc. (L, lemon; S, star; M, monstar).

surface strain-rate for each triangle of stations (Fig. 9a). Since strain-rates were not measured continuously around the boundary of the area covered by the survey, we have assumed that no isotropic points exist close to the margins of the ice stream. Strain-rates here are dominated by the shear term $\dot{\varepsilon}_{x y}$ because of side-wall drag, so this assumption seems reasonable and provides a boundary condition to help continue trajectories where data are sparse An interpretation of the pattern formed by the trajectories is shown in Figure $9 \mathrm{~b}$, where the locations of isotropic points are highlighted. It should be noted, however, that where data are sparse the patterns close to lemons and monstars can be similar (Nye, 1986). The figure is not a contour map, and no gridding or formal interpolation has been performed in areas of poor data coverage. The constraints provided by the need to fit the trajectories at all the survey points and to satisfy the boundary conditions are surprisingly strong. Attempts to fit a structurally different pattern of isotropic points have failed to produce trajectory patterns in such good agreement with the data, suggesting that the pattern shown does indeed characterize the flow at the scale of interest and should be qualitatively reproduced in any model. In the belief that any structure present on scales smaller than the resolution of the data is unlikely to be accurately reflected in the results of modelling, it has been neglected here. The density of trajectories shown is not intended to indicate a highly detailed picture but rather to aid the eye in identifying the major structural features and, although the pattern could be somewhat distorted in reality from that shown, it can be expected to be structurally very similar. 


\section{DISCUSSION}

\section{General}

The apparent increase in velocity magnitudes in the area where the two surveys overlap is small and, statistically, would appear to be only marginally significant. If there are systematic errors unaccounted for in the point positions from the TRANSIT tracking data, then the difference may, in fact, not be significant. Centroids of triangles for which strain-rates have been calculated from the two surveys coincide closely in two places: where the later longitudinal line crosses transverse line $\mathrm{D}$; and where it meets the earlier longitudinal line. In both of these places, strain-rates agree well between surveys, considering the centroids are a few hundred metres apart, and there is no evidence for a significant change. A change of velocity which was fairly constant over a wide area might be suggested, but there is really no other evidence for this.

The velocity profiles across the transverse networks $C$, $\mathrm{D}$, and $\mathrm{E}$ have been discussed in some detail by Frolich and Doake (in press) with reference to transverse gradients of horizontal shear stress and their contribution to the force balance along the longitudinal line. They concluded that this contribution, an indication of which is given by the rate of curvature of the velocity profiles, was very small for the central part of the glacier. The rates of curvature of the profiles for networks A and B are not significantly greater than that for $\mathrm{C}$ and a similar analysis shows that, here too, transverse shear-stress gradients are small and that basal stresses are the dominant resistive stresses. The presence of strongly undulating surface topography along the upper $60 \mathrm{~km}$ of the longitudinal line would also support a view of significant basal shear stresses in this area, particularly as variations in both bed topography and surface velocity appear to be correlated with it.

The profiles of velocity across lines A, B, and C appear to be broadly similar. All have fairly flat, or at least slowly curving, central parts and show a rapid decrease in velocity close to the margins. At the eastern side, all have inflections indicating maxima in shear strain-rate some way from the actual margins as estimated in Figure 2. At the western side, however, no inflections are observed (although they may exist too close to the side wall for us to resolve them) and, if we assume there is no slip at the sides, the strain-rates here must increase rapidly to very high values. Nye's (1965) analysis of glacier flow in channels of various cross-sections may provide an explanation of the asymmetry in terms of the transverse bed slopes. Whereas the side walls formed by the Ellsworth Mountains slope very rapidly with gradients of at least $45^{\circ}$, the slopes on the eastern side are much gentler, about $5^{\circ}$ for $B$ and $C$, and less than $1^{\circ}$ for $A$. The bed slope in the case of $\mathrm{A}$ is really so gentle as to be almost negligible as far as channelling fast flow is concerned, and is at least as likely to be an erosional consequence of that flow. The eastern edge of the region of high shear strain-rate on transverse line A coincides with the linear feature between Rutford Ice Stream and Carlson Inlet on Figure 3 described earlier. Curiously though, there is no crevassing visible in this area, either on the satellite image, or on the ground, although it may be that the maximum extensional strainrates of up to $3 \times 10^{-2} \mathrm{a}^{-1}$ here are just less than those needed to produce extensive crevassing, such as occurs at or near to all the other sites where the network has penetrated the margins significantly (for example, the eastern side of transverse $C$, where extensional strain-rates almost reach $\left.4 \times 10^{-2} \mathrm{a}^{-1}\right)$.

At the eastern end of transverse line $A$, the network extends for about $5 \mathrm{~km}$ beyond the linear feature described earlier and there continue to be components of flow both parallel to the main flow and also towards the centre of Rutford Ice Stream. Both components are small but statistically significant. The surface rises gently towards the eastern end of the line (a gradient of about $1 \times 10^{-3}$ ), suggesting that flow could be mainly due to internal deformation here. At site CI on Carlson Inlet, the low velocity of $7.2 \mathrm{~m} \mathrm{a}^{-1}$ also suggests that surface movement may be primarily due to internal deformation and confirms the contrast with Rutford Ice Stream expected by Doake and others (1987). The longitudinal slope of $5 \times 10^{-3}$ and the ice thickness of $1850 \mathrm{~m}$ at site CI are similar to those on Rutford Ice Stream, and strongly suggest that the velocity contrast must be due to differences in the conditions at the base of the two glaciers.

The temperature at the base of Carlson Inlet can be inferred from the application of a simple laminar-flow model. Using values for the measured surface velocity of $7.2 \pm 2.8 \mathrm{~m} \mathrm{a}^{-1}$, surface slope of $5 \times 10^{-3}$, and ice thickness of $1850 \mathrm{~m}$ gives a value for the depth-averaged flow law constant $A$ of $4.5 \pm 1.9 \times 10^{-16} \mathrm{~s}^{-1} \mathrm{kPa}^{-3}$ (assuming a power law in the form $\dot{\varepsilon}=\tau^{n}$, with $n=3$, where $\dot{\varepsilon}$ and $\tau$ are the effective strain-rate and stress, respectively). Comparing this value with the one recommended by Paterson (1981) of $5.2 \times 10^{-16} \mathrm{~s}^{-1} \mathrm{kPa}^{-3}$ at a temperature of $-10^{\circ} \mathrm{C}$ suggests that the average column temperature at site $\mathrm{C}$ is around $-12 \pm 4^{\circ} \mathrm{C}$. At this site, a steady-state column model for the temperature profile (Paterson, 1981) gives the difference between surface and basal temperatures as $12 \mathrm{~K}$ for an annual accumulation of $0.7 \mathrm{~m} \mathrm{a}^{-1}$, an assumed geothermal heat flux of $6 \times 10^{-2} \mathrm{~W} \mathrm{~m}^{-2}$, and a thermal diffusivity of $1.15 \times 10^{-6} \mathrm{~m}^{-2} \mathrm{~s}^{-1}$. For a surface temperature of $-26^{\circ} \mathrm{C}$, the basal temperature would then be around $-14^{\circ} \mathrm{C}$. Considering that only very simplified models have been used and that we expect the average column temperature calculated from the surface velocity to be quite strongly biased towards the basal value, the agreement between the two calculations is sufficiently close to suggest that there is a frozen base at site $\mathrm{CI}$ and that all the movement can indeed be accounted for by internal deformation.

An implication of this result is that an estimate can be made of the relative contributions of basal sliding and internal deformation to the surface velocities measured along Rutford Ice Stream. To obtain an upper bound for the velocity due to internal deformation, we may use a value of $A$ for a temperature of $0^{\circ} \mathrm{C}$ to simulate conditions where basal sliding can occur (Bindschadler, 1984). The resulting values for the surface velocity show that, even for this extreme example, sliding must dominate the flow over most of the network. At the upper end of the network, where surface slopes are higher and more variable, the deformation velocity could approach the sliding velocity in magnitude. Values for the sliding and deformation components of velocity, however, are not reliable enough to infer anything other than a possible trend from them.

\section{Strain-rate pattern}

Nye (1983) described an idealized pattern for strain-rate trajectories that could be expected on a realistic glacier. Local minima in velocity must be rare on the body of a glacier, and the velocity field can be approximated to a series of alternating saddle points and maxima in velocity, where these correspond to lemons or monstars. This is the type of pattern delineated by Meier and others (1985) for Columbia Glacier and the one seen on Rutford Ice Stream in Figure 9b, although lateral variations and attendant wandering of the stress centre line cause considerable distortions to the symmetry.

Down the longitudinal line, a lemon (L1) occurs close to a local maximum in velocity at $4 \mathrm{~km}$, and a star (S1) occurs close to the longitudinal minimum at $30 \mathrm{~km}$. There is also a monstar (M) towards the western extremity of the transverse network C, approximately over the thickest and fastest-moving ice on this line.

Another star (S2) and lemon (L2) are longitudinally close to each other, although $\mathrm{S} 2$ is probably a little up-stream of L2. These features do not coincide with any obvious turning points in the longitudinal velocity profile in Figure 6, but S2 roughly coincides laterally with the maxima in velocity on transverses $\mathrm{C}$ and $\mathrm{D}$ (Fig. 7).

The area enclosed by the dashed line coincides with the surface knoll visible on the satellite image (Fig. 3) and step in bedrock at $90 \mathrm{~km}$ in Figure 4b. The flow is partially diverted around this knoll, making the strain-rate trajectories pattern complicated and difficult to resolve with the present data density. Survey data at a higher density, reducing the area over which velocity gradients must be averaged to give each value of strain-rate, would be needed to resolve the pattern in this area. We can, however, make some deductions concerning the pattern within the dashed boundary. Tracing a closed path around the boundary shows that the strain-rate trajectory suffers no net rotation. This implies that the number of lemons and monstars contained 
within it must equal the number of stars. Frolich and others (1987) showed values of $\dot{\varepsilon}_{x x}, \dot{\varepsilon}_{y y}$, and $\dot{\varepsilon}_{x y}$ along the longitudinal line in this area. The condition $\dot{\varepsilon}_{x x}=\dot{\varepsilon}_{y y}$ is satisfied at at least three points. The second condition, $\dot{\varepsilon}_{x y}=0$ is also satisfied near two of these points, and so there are probably at least two isotropic points within the boundary. If the strain-rate measurements made close to the knoll had not been included in the data set, the pattern could easily have been interpolated across this area. This observation raises the question whether similar features exist elsewhere on the network where groups of closely spaced cancelling isotropic points are present, but are not identified at this scale due to sparsity of data. A second surface knoll, associated with the grounding line (Stephenson, 1984), also distorts the flow to some extent. However, the distortion is apparently not sufficient to produce any isotropic points, but merely causes the strain-rate trajectories to rotate a little locally. Although the pattern shown in Figure $9 \mathrm{~b}$ fits the data, there may be other possibilities that we are unable to define because of lack of data near the stress centre line. In particular, the pattern does not show an isotropic point related to the velocity maximum above the grounding line at $110 \mathrm{~km}$ (Fig. 6).

\section{CONCLUSIONS}

Conventional ground-based survey observations have been combined with TRANSIT satellite-tracking data in a systematic way to give positions and velocities for stations in two large survey networks on Rutford Ice Stream.

There is some evidence for an increase in velocity in recent years where two surveys overlap about $20 \mathrm{~km}$ above the grounding line, although statistically the change of about $7 \mathrm{~m} \mathrm{a}^{-1}$ is only marginally significant.

Velocity profiles across the ice stream show that, at least for the central part of the ice stream, restraint from the base must dominate that from lateral shear in balancing the gravitational driving force. Variations in surface slope and velocity in this area suggest that longitudinal stress gradients may also be significant, but we have yet to quantify these properly.

A marked asymmetry in the velocity gradients at the ends of the three transverse networks furthest up-stream (A, $\mathrm{B}$, and $\mathrm{C}$ in Figure 2) may be explained in part by differences in transverse bed slopes for the western and eastern margins. In the case of the line furthest up-stream, however, the bed slope on the eastern side is negligible and a change in basal conditions is needed to explain any large transverse gradient in velocity. A simple laminar flow model, applied to a site on Carlson Inlet, supports this view, suggesting that the ice is frozen to its bed here and that rapid flow on Rutford Ice Stream must be largely due to basal sliding.

A pattern of strain-rate trajectories has proved useful in providing a general impression of the flow and in helping to assess the quality of the strain-rate data. The pattern for the most part agrees with what would be expected for an idealized geometry, except for where lateral variations and localized topographical features provide additional complexity. It would therefore appear to provide a conveniently small number of characteristic features against which to test future attempts to model the icestream flow.

\section{ACKNOWLEDGEMENTS}

We thank Mr N.A.G. Leppard of the Directorate of Military Survey for arranging the post-processing of our satellite-tracking data and Professor J.F. Nye for helpful discussion and enlightenment.

\section{REFERENCES}

Bindschadler, R.A. 1984. Jakobshavns Glacier drainage basin: a balance assessment. J. Geophys. Res., 89(C2), 2066-2072.

Doake, C.S.M., R.M. Frohlich, D.R. Mantripp, A.M. Smith, and D.G. Vaughan. 1987. Glaciological studies on Rutford Ice Stream, Antarctica. J. Geophys. Res., 92(B9), 8951-8960.

Frolich, R.M. and C.S.M. Doake. 1988. Relative importance of lateral and vertical shear on Rutford Ice Stream, Antarctica. Ann. Glaciol., 11, 19-22.

Frolich, R.M., D.R. Mantripp, D.G. Vaughan, and C.S.M. Doake. 1987. Force balance of Rutford Ice Stream, Antarctica. International Association of Hydrological Sciences Publication 170 (Symposium at Vancouver - The Physical Basis of Ice Sheet Modelling), 323-331.

McDonald, J. and I.M. Whillans. 1988. Comparison of results from Transit satellite tracking. Ann. Glaciol., 11, 83-88.

Meier, M.F., L.A. Rasmussen, R.M. Krimmel, R.W. Olsen, and D. Frank. 1985. Photogrammetric determination of surface altitude, terminus position, and ice velocity of Columbia Glacier, Alaska. U.S. Geol. Surv. Prof. Pap. $1258-\mathrm{F}$.

Nye, J.F. 1965. The flow of a glacier in a channel of rectangular, elliptic or parabolic cross-section. J. Glaciol., 5(41), 661-690.

Nye, J.F. 1983. Monstars on glaciers. J. Glaciol., 29(101), 70-77.

Nye, J.F. 1986. Isotropic points on glaciers. J. Glaciol., 32(112), 363-365.

Paterson, W.S.B. 1981. The physics of glaciers. Second edition. Oxford, etc., Pergamon Press.

Stephenson, S.N. 1984. Glacier flexure and the position of grounding lines: measurements by tiltmeter on Rutford Ice Stream, Antarctica. Ann. Glaciol., 5, 165-169.

Stephenson, S.N. and C.S.M. Doake. 1982. Dynamic behaviour of Rutford Ice Stream. Ann. Glaciol., 3, 295-299.

Wager, A.C., C.S.M. Doake, J.G. Paren, and J.L.W. Walton. 1980. Survey reduction for glacier movement studies. Surv. Rev., 25(196), 251-263.

Whillans, I.M., J. Bolzan, and S. Shabtaie. 1987. Velocity of ice streams B and C, Antarctica. J. Geophys. Res., 92(B9), 8895-8902. 